\title{
An Evaluation of the Normal Lymphocyte Transfer Test in Man*
}

\author{
D. B. Amos, P. J. Nicks, N. Peacocke, and H. O. Sieker \\ (From the Division of Immunology and Department of Medicine, Duke University Medical \\ Center, Durham, N. C.)
}

Skin or kidney grafts often fail because the antigenic difference between donor and recipient is so great that immunosuppressive therapy is ineffective or must be pushed beyond the lethal limit. The number of transplantation antigens on tissue is large, and the chance of obtaining complete compatibility between donor and recipient is correspondingly low. However, from animal experiments it is known that certain antigens are more effective at inducing immunity than others. Incomplete compatibility is of less account if the antigens not matched are weak. There is therefore much interest in the development of a test that will discriminate between major and minor grades of incompatibility. Several methods are being investigated concurrently. These include serological tests for leukocyte and tissue antigens (1-4), a comparison of the speed at which a third party will reject skin from the patient as compared to the reaction against potential donors (5, 6 ), mixed cell agglutination using kidney cells in tissue culture $(7)$, and the alteration observed in lymphocytes when exposed to foreign cells $(8,9)$. Another test that has been suggested recently is the normal lymphocyte transfer test (10). Lymphocytes from the patient are injected intradermally into each of a number of donors. The greater the antigenic diversity between patient and donor, the greater, it is thought, will be the reactive intensity of the transferred lymphocytes to antigens in the skin at the transfer site.

Brent and Medawar, who introduced this test, found a positive correlation between lymphocyte reactivity and skin graft rejection in guinea pigs (10). They have extended their observations to hybrid animals and find that cells from one of

* Submitted for publication May 1, 1964 ; accepted October 19, 1964.

Supported by U. S. Public Health Service grants AI K6 18399 and GM 10356. the parental strains will react when injected into the other parental strain or into the hybrid. Hybrid cells do not react against the parent (11). This finding is compatible with the hypothesis that the inflammatory response is immunological in nature and that it is primarily produced by the injected lymphocytes reacting against the new host. Hybrid cells contain the antigens of the parent and thus do not react; parental cells lack some antigens present in the hybrid and so will react. The genetic and immunologic bases of the test appear to be well established in the guinea pig.

When cells from a normal subject are injected into a series of normal human volunteers, there are differences in the degrees of inflammation produced. Gray and Russell injected lymphocytes from a potential graft recipient, $R$, into a series of subjects, $D_{1}, D_{2}, D_{3}$, etc. A strong and a weak reactor were chosen to give skin to $R$. Skin from the strong reactor was more rapidly rejected than skin from the weak reactor $(12,13)$.

In their original paper (10) Brent and Medawar suggested that nonspecific factors might influence the reaction in man. Bridges, Nelson, and McGeown have already shown that cells from a uremic subject may be less reactive than cells from a normal subject (14), yet these are the very subjects most in need of a test for compatibility. The immunological reactivity of humans is often altered by disease, and actual immunization is a common sequel to repeated pregnancies (15) or blood transfusions (16).

Because of the theoretical importance of this reaction in which normal lymphocytes apparently behave as "immunocytes" within 24 hours of transfer, and because of its great clinical significance, we have performed a series of tests designed to explore further the immunological parameters of the test in man.

In these experiments advantage has been taken 
of the known cross-reactivity between unrelated subjects. Leukocytes from one donor will specifically sensitize against skin from the same donor and also against skin from many other donors (5). Antibodies found after parturition or blood transfusion also show a wide and complex pattern of reactivity $(15,16)$. Thus, if a recipient has been sensitized by the injection of cells from three or more randomly selected individuals, it may be confidently assumed that he will react strongly against virtually any randomly selected donor.

\section{Methods}

Test subjects. Three classes of subjects have been used. 1) Normal students, with a previous history of uneventful blood donation, who had not received blood or a skin graft. 2) Patients with an incurable but not incapacitating lung disease. These patients were ambulatory; most of them had an early but inoperable carcinoma of the lung. All were well nourished and free from obvious infection or complications of the disease. 3) $\mathrm{Pa}$ tients who were admitted for acute surgical procedures such as appendectomy or lacerations. ${ }^{1}$ In this group of Negro subjects induration was minimal, and erythema was impossible to read except in albino or relatively fairskinned individuals; therefore, further experiments have been confined to white males. In no case were cells from a patient administered to a normal subject, but cells from one student were given to many of the patients to attempt to provide a form of standard reference.

Preparation of lymphocytes. In the first experiments phagocytic cells were separated with black magnetic oxide of iron; subsequently nylon columns were used to remove the majority of polymorphonuclear cells. Heparin, 1,000 $\mu$ per $100 \mathrm{ml}$ blood, was used as anticoagulant; all glassware was siliconized with Siliclad.

Separation with iron. The heparinized blood was mixed with $2.5 \mathrm{ml}$ of $3 \%$ gelatin (Plasmagel ${ }^{2}$ ) for each $10 \mathrm{ml}$ blood. After sedimentation for 30 minutes at room temperature in a siliconized tube, the supernatant fluid containing leukocytes, platelets, and some erythrocytes was centrifuged at $83 \times g$ for 10 minutes. The cell pellet from each $10 \mathrm{ml}$ of blood was resuspended in about $0.2 \mathrm{ml}$ platelet free plasma and allowed to resediment for 30 to 40 minutes. The leukocyte-rich supernatant liquid was diluted to $5 \mathrm{ml}$ with platelet free plasma containing $0.1 \mathrm{ml} 2 \%$ black magnetic oxide of iron and $2 \%$ gum arabic in Ringer's solution and placed in a $20-\mathrm{ml}$ vaccine bottle. The bottle was placed on its side in a shaking water bath at $40^{\circ} \mathrm{C}$ for 30 minutes; the cell suspension was then transferred to a $12-\mathrm{mm}$ siliconized tube and held against the poles of a permanent magnet.

1 These patients were involved in a few pilot studies with Dr. W. Weaver.

${ }^{2}$ Laboratoire Roger Bellon, Neuilly, Seine, France.
Iron-containing cells were drawn to the side of the tube, and the remainder of the suspension was placed in a similar tube and again exposed to the magnet; the cell suspension remaining generally consisted of $95 \%$ or more lymphocytes. The lymphocyte suspensions were centrifuged at about $100 \times g$ and resuspended in physiological saline to a concentration of $5 \times 10^{7}$ per $\mathrm{ml}$. The method frequently worked well with cells from normal subjects and was notable in that all classes of phagocytic cells including polymorphonuclear neutrophils, monocytes, and eosinophils together with most of the platelets were removed, leaving a virtually pure lymphocyte suspension with an occasional basophil. However, yields were somewhat erratic, and lymphocytes were sometimes trapped in excessive numbers; the amount of iron needed had to be adjusted to suit the proportion of polymorphs, and disappointing results were obtained in some of the disease states.

In later experiments, separation with nylon fibers has been used. The method is essentially that of Greenwalt, Gajewski, and McKenna (17). One hundred $\mathrm{ml}$ of blood was drawn into a vacuum bottle containing 5,000 U of heparin free from preservative and then passed under slight positive pressure through a column of nylon. DuPont nylon, 3 denier, $1 \frac{1}{2}$ inch, no. 200, was washed in Duponol, dried, weighed into $4.0-\mathrm{g}$ amounts, teased by brushing between two nylon hair brushes, and packed into a column $15 \times 1.5 \mathrm{~cm}$. The column was washed in Ringer's solution, capped with a vaccine stopper, and a glass bell attached to the lower end. The assembly was autoclaved wet. The blood was run through a tygon tube into the column, under sufficient pressure to give a flow of about $5 \mathrm{ml}$ per minute. The effluent from the column was collected into $100-\mathrm{ml}$ graduated cylinders containing $10 \mathrm{ml}$ Alsevers solution. The first $75 \mathrm{ml}$ of filtrate generally contained 97 to $99 \%$ lymphocytes and most of the red cells. In some cases the column could be washed through with saline to give a total of $150 \mathrm{ml}$ of filtrate with very little contamination with polymorphonuclear neutrophils. The lymphocyte suspension was poor in platelets but did contain eosinophils and monocytes.

Gelatin was added in the proportion of $30 \mathrm{ml}$ to 100 $\mathrm{ml}$ filtrate, and the red cells were allowed to settle for 45 minutes. The supernatant fluid was centrifuged at about $100 \times g$ for 10 minutes, and the pellet was resuspended in $1.0 \mathrm{ml}$ of platelet free plasma and allowed to resediment for 15 minutes. This second sedimentation removed the vast bulk of the remaining red cells that formed rouleaux in this concentrated suspension. The leukocyte layer was again removed and resuspended in heparinized saline to a final concentration of $5 \times 10^{7}$ per $\mathrm{ml}$ or $2.5 \times 10^{7}$ per $\mathrm{ml}$. Any cells not required for the test were used in a parallel series of tissue culture experiments.

Polymorphonuclear leukocytes. Although a high yield of polymorphonuclear leukocytes (PMN) could have been obtained with iron separation, we felt that these cells could not be considered representative. Various methods 
of separation from nylon fibers or glass beads were tried, but the most satisfactory preparations were obtained by simple sedimentation. Fifteen $\mathrm{ml}$ of whole blood was drawn in $1.5 \mathrm{ml}$ of $5 \%$ EDTA in saline. Leukocyte separation was obtained by the gelatin sedimentation previously described. A $25 \%$ sterile sucrose solution was diluted $1: 5$ with sterile normal saline. The crude leukocytes were removed from the gelatin and resuspended in $0.5 \mathrm{ml}$ of this solution. The lymphocytes were allowed to settle for 20 minutes at room temperature; then the supernatant fluid was removed and added to $1 \mathrm{ml}$ of normal saline. After 15 minutes sedimentation the cells on the bottom were predominantly PMN. This sedimentation could be repeated with a resulting increase of purity and decrease in yield. The average purity was $97 \%$ and yield was $10 \times 10^{\circ}$ with this method.

Experimental design. Lymphocyte suspensions were injected via a no. 27 or 30 needle into the anterior aspect of the forearm. Each recipient usually received two injections from each of a series of donors, one injection of $5 \times 10^{6}$ and one of $2.5 \times 10^{6}$ cells. Each donor served in turn as recipient for cells from other participants in the experiment.

Erythema or induration as a criterion of measurement. The measurement of either erythema or induration is subject to considerable error, and a more objective measurement such as release of radioactivity would be preferable. Erythema is simple to read in most subjects but is of little value in deeply pigmented skins and is greatly affected by even gentle rubbing. Induration is a more satisfactory measure when the edges are sharply defined. The margins were diffuse in this type of reaction, especially in some subjects. Both measurements were recorded and paralleled each other during the first 48 hours; neither had any obvious advantage. Occasionally induration was absent when there was mild erythema, especially after the injection of autologous cells. In old lesions erythema and induration were coextensive.

Erythema was measured after 8 hours; induration and erythema were recorded every 24 hours for up to 8 days. $^{3}$ Reactions, erythema or induration, were scored as the mean of two diameters at right angles.

Controls. Five classes of controls have been included besides differential counts to check on the purity of the suspension and trypan blue uptake to test the viability of the cells. All suspensions contained over $90 \%$ lymphocytes. Viability was often over $99 \%$ and always over $95 \%$.

1) In the controls for cutaneous hypersensitivity to injury, needle prick and saline injection were negative.

2) In the controls for nonspecific irritants in the plasma, the final supernatant plasma, containing anticoagulants and gelatin but without cells, was nonreactive.

3) Cell suspensions were injected back into the autologous host as a control for nonspecific effects in the cells themselves. In most normal subjects and in acute surgical patients there was a positive reaction to lymphocyte suspensions at 8 hours, but the inflammation subsided rapidly.

3 The majority of readings was made by Dr. Amos.
With only three exceptions reactions at 48 hours were trivial or negative. Autologous reactions were, however, common in the lung disease patients. Eight of the 21 tested gave a positive reaction at 48 hours; the tendency was most obvious in those patients who were generally hyperreactive.

4) Since humans vary greatly in their response to a variety of cutaneous irritants, a polyvalent bacterial suspension was given intradermally to a number of normal subjects. All responded, but there was no close correlation between the response to the vaccine and the average response to a number of cell suspensions given at the same time.

5) In the first experiment involving patients there were wider variations in the range of responses to lymphocyte suspensions than had been observed in normal subjects. Cells from a standard donor were therefore given as an additional control in subsequent experiments.

\section{Results}

Reproducibility within an experiment. Nine subjects were each given two injections of $5 \times 10^{6}$ cells from the same donor. The resultant lesions were measured daily for up to 5 days. Differences among the pairs of injections were surprisingly small. The mean difference for 47 pairs of determinations at the same dose level was $1.9 \mathrm{~mm}$, and the standard deviation of the differences was \pm 1.5 . The average diameter of all lesions in this series was $9.1 \mathrm{~mm}$. The test can therefore have good reproducibility within an experiment. Some results abstracted from the experiment are represented in Figure 1.

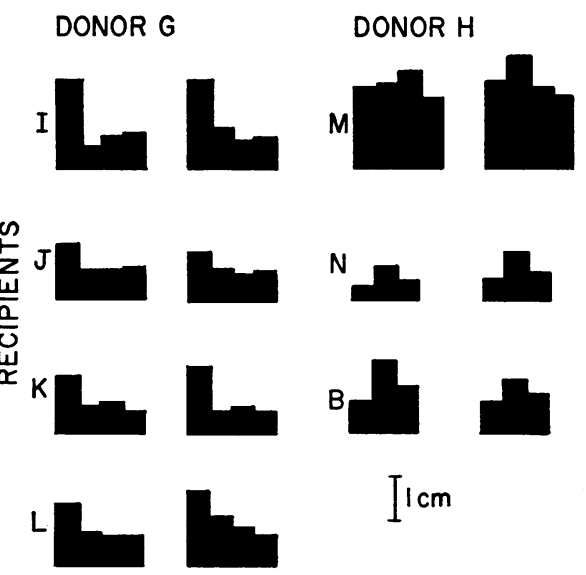

Fig. 1. Comparison OF the inflammatory RESPONSE IN SIX NORMAL ( $I$ TO $N$ ) AND ONE IMMUNE (B) SUBJECT RECEIVING DUPLICATE INJECTIONS OF $5 \times 10^{8}$ LYMPHOCYTES FROM ONE OF TWO DONORS. (Erythema measured at successive 24 hourly intervals.) 


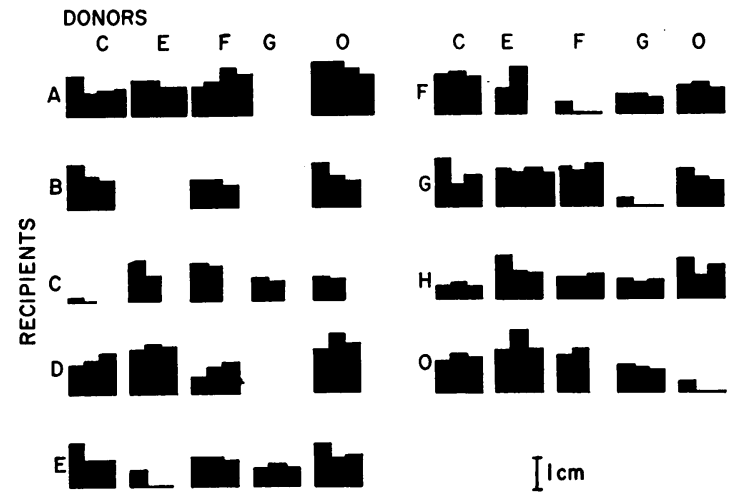

Fig. 2. REACtions OF NINE SUBJECTS FROM EXPERIMENT 4, EIGHT PREVIOUSLY SENSITIZED AND ONE (O) NORMAL, INJECTED WITH CELLS FROM FOUR IMMUNE AND ONE NONIMMUNE SUBJECT. (Erythema measured at successive 24 hourly intervals.)

Lymphocyte transfer in healthy subjects. Potential organ recipients are chronically ill; most have received many blood transfusions, and some have even been previously grafted and have rejected a graft. A proportion of the potential donors are also not immunologically normal but have themselves been sensitized by pregnancy or by transfusion. It appeared desirable to see how variations in the immune status of donor and recipient affect the test and how reproducible the results are under varying conditions of immunization.

A simple series of cross-reactions was set up in the first experiment. Four students, A, B, C, and $\mathrm{D}$, were each given $5 \times 10^{6}$ autologous cells and $5 \times 10^{6}$ cells from each of the other three participants. Induration and erythema were measured daily. Twelve days later Subjects A, B, and D, together with a normal control, E, participated in a second test. In this experiment three of the recipients could be considered to be immune and, by analogy with animal experiments, would have been expected to give heightened or accelerated reactions. Cells from $\mathrm{A}, \mathrm{B}$, and $\mathrm{D}$ were also expected to give exaggerated responses in $\mathrm{E}$. In a third experiment Subject $C$ from the first experiment was tested with three additional normal subjects, $F, G$, and $H$.

The reactions involving either the cells from normal subject $\mathrm{E}$ or involving $\mathrm{E}$ as recipient in experiment 2 were not remarkable. $E$ appeared to be no less reactive than the other subjects who had presumably been sensitized. The reactions of the remaining subjects with each other were roughly comparable to those observed in the first experiment, and only one reaction, $\mathrm{B}$ cells into $\mathrm{D}$, was markedly different, converting from a doubtful reaction $(2 \mathrm{~mm})$ to moderately positive $(8 \mathrm{~mm})$.

Ten weeks later, experiment 4 involving most of the participants from the three previous experiments, together with one additional normal subject, was carried out. Twenty-one of the combinations had been tested twice, and a larger scale comparison could be made (Figure 2). Of 21 tests in which cells from a given donor had been tested twice or more in the same recipient, only 12 gave agreement within $\pm 3 \mathrm{~mm}$. Since most readings fall within the range 8 to $12 \mathrm{~mm}$, this would have been expected by chance. Nine of the readings differed by $5 \mathrm{~mm}$ or more, and in three instances the differences exceeded $8 \mathrm{~mm}$. The direction of the change was not constant; four of the reactions were stronger and five were weaker. The first three experiments had been carried out with cells separated with iron; in the last experiment nylon was used. The different methods of separation do not appear to have resulted in any systematic error, since some reactions agreed with the two methods, some were stronger with the nylon-prepared cells, and some with the iron method. The poor reproducibility among experiments contrasts strongly with the excellent reproducibility within an experiment reported above.

The question of how immunity could influence the result was investigated in experiment 5 . Since all the participants had been heavily immunized with a variety of cells, it was thought that their immunological reactivity should be uniformly high and that a reaction corresponding to the white graft phenomenon might be manifested if the test were repeated after a very short time lapse. Six days after the subjects had been injected for experiment 4 , they were again challenged. Indeed, the results of this experiment stood out from all previous tests. Many of the cutaneous reactions were atypically brisk, being strong at 8 hours, reaching a maximum at 24 hours, and largely subsiding by 48 hours. The mean diameter of the erythema was $14 \mathrm{~mm}$ at 24 hours, but after 48 hours had fallen to less than $5 \mathrm{~mm}$. The corresponding values for all experiments on healthy 
subjects after 24 hours and 48 hours were 12.3 and 10.5 , respectively. In this experiment erythema was much more extensive than induration after 24 hours, the ratio of erythema to induration being $2.3: 1.0$, but after 48 hours the ratio had returned to the more usual level of $1.1: 1.0$.

None of the previous experiments had given a clear indication that the reaction in humans was of the graft versus host type. To test this possibility directly, six students were admitted to the next experiment (no. 6). Three had been previously immunized four times, and three were normal subjects who had never received a transfusion or graft of any kind. It was therefore possible to test four different combinations. Immune cells were injected into immune recipients (Figure 3, 1 ), immune cells into normal subjects (Figure 3, 3 ), normal cells into immune subjects (Figure 3, 2 ), and normal cells into normal subjects (Figure $3,4)$.

The greatest over-all response was obtained when cells from normal donors were injected into normal or immune recipients, and the least reactivity was observed when immune cells were injected into normal or immune recipients. A later repetition of this experiment (experiment 7) using four normal and three immune subjects gave essentially similar results. A summary of values obtained in these two experiments after 24 and 48 hours is presented in Table I.

Comparative studies with polymorphonuclear leukocytes, platelets, and fresh or frozen lymphocytes. In the course of the previous series of experiments the possibility that host versus graft reactions formed part of the basis for the reactions had been considered. Thought was given to the use of a cell that might share many antigens with

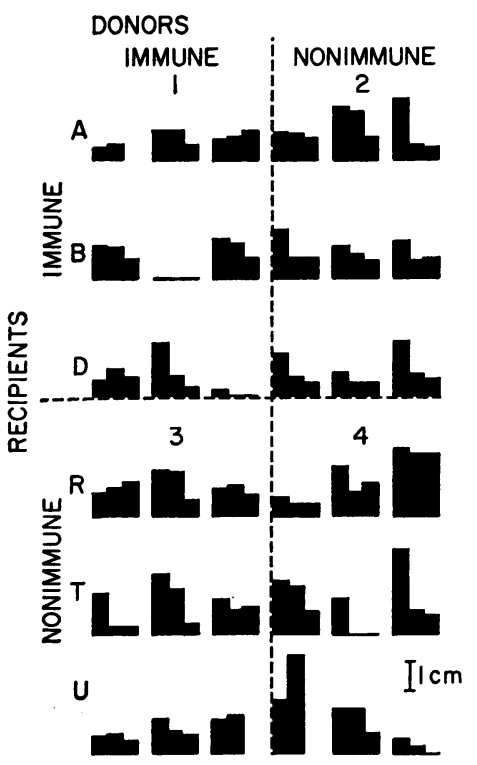

Fig. 3. A COMPARISON OF FOUR IMMUNOLOGICAL RELATIONSHIPS (EXPERIMENT 6). 1) Immune cells into immune recipients. 2) Nonimmune cells into immune recipients. 3) Immune cells into normal subjects. 4) Normal cells into normal subjects. (Erythema measured at successive 24 hourly intervals.)

the lymphocytes, but that would itself be immunologically inert. Most easily available were other cells from the blood. Polymorphonuclear leukocytes and platelets were chosen for study. In addition, we thought that frozen and thawed lymphocytes should retain antigenic potency while losing their capacity to react against the skin of the recipient.

Polymorphonuclear leukocytes (PMN) were injected into three of the patients with pulmonary disease. Inflammation about half as extensive as that produced by lymphocytes from the same donor was seen in one recipient; another recipient

TABLE I

Comparison of normal and previously immunized subjects

\begin{tabular}{|c|c|c|c|c|c|c|c|c|}
\hline \multirow{2}{*}{ 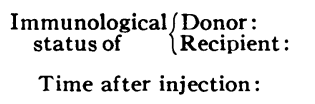 } & \multicolumn{2}{|c|}{$\begin{array}{l}\text { Normal } \\
\text { Normal }\end{array}$} & \multicolumn{2}{|c|}{$\begin{array}{l}\text { Normal } \\
\text { Immune }\end{array}$} & \multicolumn{2}{|c|}{$\begin{array}{l}\text { Immune } \\
\text { Normal }\end{array}$} & \multicolumn{2}{|c|}{$\begin{array}{l}\text { Immune } \\
\text { Immune }\end{array}$} \\
\hline & $24 \mathrm{hr}$ & $48 \mathrm{hr}$ & $24 \mathrm{hr}$ & $48 \mathrm{hr}$ & $24 \mathrm{hr}$ & $48 \mathrm{hr}$ & $24 \mathrm{hr}$ & $48 \mathrm{hr}$ \\
\hline & \multicolumn{2}{|c|}{$m m$} & \multicolumn{2}{|c|}{$m m$} & \multicolumn{2}{|c|}{$m m$} & \multicolumn{2}{|c|}{$m m$} \\
\hline $\begin{array}{l}\text { Experiment } 6 \\
\text { Experiment } 7 \\
\text { Combined mean/day } \\
\text { Combined mean/group }\end{array}$ & $\begin{array}{l}13.6^{*} \\
19.8 \\
15.7\end{array}$ & $\begin{array}{l}13.0 \\
16.0 \\
14.0\end{array}$ & $\begin{array}{l}14.6 \\
12.1 \\
13.1\end{array}$ & $\begin{array}{r}8.0 \\
13.8 \\
11.5\end{array}$ & $\begin{array}{r}8.0 \\
11.6 \\
9.6\end{array}$ & $\begin{array}{l}7.4 \\
9.4 \\
7.9\end{array}$ & $\begin{array}{r}10.8 \\
8.2 \\
9.5\end{array}$ & $\begin{array}{l}9.3 \\
7.5 \\
8.4\end{array}$ \\
\hline
\end{tabular}

* All results expressed as mean of 2 diameters of erythematous lesion. 


\section{DONOR H}
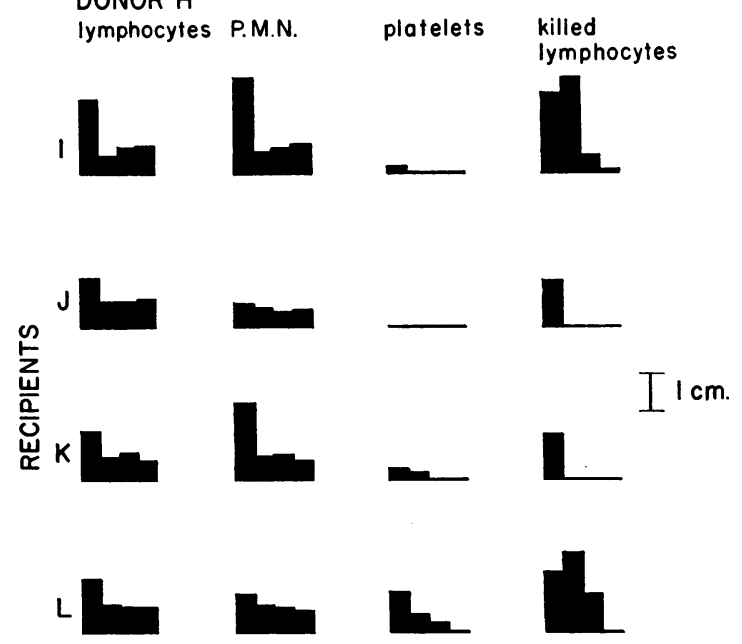

Fig. 4. Reactions following the injection of VARIOUS CELLULAR ELEMENTS. Lymphocyte and polymorphonuclear leukocyte (PMN) injections followed after 9 days by platelets and frozen lymphocytes from same donor. (Erythema measured at successive 24 hourly intervals.)

reacted to lymphocytes but not to PMN. The third subject was the autologous control and was negative to both.

In another experiment, seven normal subjects were divided into two groups; the four subjects in group $A$ received two injections each of $5 \times$ $10^{6}$ lymphocytes and four injections of $\mathrm{PMN}$ at doses of $5,2.5,1.25$, and $0.5 \times 10^{6}$ in $0.1 \mathrm{ml}$ from Subject G. Group B received a similar course of injections from Subject $H$. In this experiment, strong reactions to lymphocytes were matched by strong reactions to $\mathrm{PMN}$ in both induration and erythema (Figure 4) ( $\mathrm{X}^{2}$ for 6 degrees of freedom was $0.65, \mathrm{p}>0.99$ ). All subjects responded to $1.25 \times 10^{6}$ or more PMN, and all but one reacted at the $0.5 \times 10^{6}$ level. Autologous controls were negative. The PMN suspensions were not pure but contained less than $10 \%$ lymphocytes; at the lowest dose level, therefore, less than $5 \times 10^{5} \mathrm{lym}$ phocytes were injected as contaminants.

After nine days, the four subjects from group A and two subjects from group B were challenged with platelets and with three times frozen and thawed lymphocytes from the original immunizing donor, together with similar cells from seven other subjects. One of the subjects from group A responded briskly to all platelets injected, most of the lesions being over $10 \mathrm{~mm}$ in diameter at 48 hours. Another subject responded with small lesions of from 3 to $5 \mathrm{~mm}$ with five of the platelet suspensions at 24 hours and with only a minimal reaction. $(2 \mathrm{~mm})$ to the original donor at 48 hours ; the remaining two subjects remained essentially negative. In group $B$, both subjects responded to platelets. Again one subject responded to all eight injections, whereas the other reacted more feebly and to only six. There was nothing to distinguish the reaction to the specific immunizing donor from the reaction to platelets from the other six subjects. In this experiment reactions to frozen and thawed lymphocytes were atypically brisk, erythema reaching a maximum of over 40 $\mathrm{mm}$. This unusual reaction was tentatively attributed to the release of permeability factors from the damaged lymphocytes (some reactions are illustrated in Figure 4).

In a third experiment in which different varieties of cells were compared, four normal and two previously immunized subjects were injected with both a highly purified lymphocyte suspension and a suspension rich in PMN from the same donor. Two normal subjects received cells from normal donors, and the others received cells from the immune donors. Each of the two immune subjects received cells from one of the normal and from the other immune subject. The cells were administered over a range from $10^{5}$ to $5 \times 10^{6}$ cells. Of the two normal subjects given normal cells, one responded to both lymphocytes and $\mathrm{PMN}$; the other responded less strongly to lymphocytes and only at the highest dose level to PMN. The two normal subjects receiving cells from previously immunized donors both responded to very small doses of cells. One had a relatively weak reaction to lymphocytes and a very feeble reaction to $\mathrm{PMN}$; the other reacted briskly with both.

One of the immune recipients presented an interesting pattern. The reactions with lymphocytes from the normal and immune donors were very similar; there were reactions to PMN from one donor (the immune) in four of the six injection sites and reactions only to the highest cell concentration with cells from the other donor.

The final experiment in this series gave further information on the host versus graft aspect of the reaction. Seven subjects, four normal and three immune, were tested simultaneously with frozen and thawed lymphocytes and with PMN. The 
lymphocyte suspensions were all of $98 \%$ or greater purity; the PMN suspensions averaged $97 \%$ purity, the poorest containing $94 \%$, the best over $99 \%$ PMN. The average cell doses were $5 \times 10^{6}$ lymphocytes, $4 \times 10^{6}$ frozen and thawed lymphocytes, and $1 \times 10^{6} \mathrm{PMN}$. The most highly contaminated PMN suspension could not have contained more than $6 \times 10^{4}$ lymphocytes and the purest less than $10^{4}$.

The results obtained with lymphocytes have been mentioned in the previous section as experiment 7 of that series. As commented on above, reactions were obtained with all the fresh lymphocyte suspensions. The reactions were briskest with normal subjects. All recipients responded to at least one PMN suspension. One normal and one immune recipient responded to all six allogenic cells, two normals and two immunes responded to five of the six foreign cells, and one normal responded to only four. In several instances there was a delay in onset of the reaction. Four normal recipients did not respond to a given PMN suspension until the second day, and two reactions did not become positive until the third day. Once the lesions had appeared they tended to persist, many for as long as 6 days. The inflammation in the immune recipients, like the response to lymphocytes in this group, was generally less intense and less long lasting. Surprisingly, many of these reactions to $P M N$ in immune subjects were also delayed in onset; four did not appear until the second day, and five were delayed until the fifth day and were fading by the sixth day.

Relatively few reactions were seen against the frozen and thawed cells in this experiment. Two of the normal and one of the immune recipients did not react to any of the suspensions, one normal subject reacted to cell suspensions from only two, and the other reacted weakly to those from three donors. Of the other two immunes, one reacted to only one cell, transiently, and the final subject reacted to five of the six suspensions, one of the reactions being weak and delayed in onset. This particular subject reacted to all six of the PMN suspensions and was the last of the subjects receiving comparable injections to develop detectable antibody.

Lymphocyte injections and the production of antibodies. After the recipients had received two courses of lymphocyte injections totaling about $50 \times 10^{6}$ cells from several donors, their sera were tested for the presence of leukoagglutinins. One serum was weakly positive at this time and reacted with the cells of two of the lymphocyte donors to a titer of $\frac{1}{2}$.

With progressive immunization, all of the repeatedly immunized recipients are now producing antibodies. Antibody activity has been detected through leukoagglutination (18) and through cytotoxicity tests (19). The two types of antibody do not have the same pattern of reactivity, and at least some of the sera are believed to have more than one agglutinin. The cross-reactions are shown in Table II. The highest titer that has been reached is $1 / 128$ in the cytotoxicity test. These antibodies are being studied further and will be the subject of a separate report.

Experiments on patients with lung disease. Twenty-three patients with lung disease were divided into five groups. The first experiment involved four subjects. Each participant was tested with cells from the other three and with autologous cells. This group of subjects yielded a rather unexpectedly weak series of reactions. As an external control on the reactivity of the lymphocytes used for future experiments, cells from a normal healthy subject were injected into each of the remaining 19 subjects.

Responses in the patients, with three exceptions, appeared to be depressed as compared to the average lesion in normal subjects (Figure 5). Whereas the average of 43 reactions of nonimmunized normal subjects to normal cells was approximately $12.4 \mathrm{~mm}$, the average for patients, excluding the three hyperreactive recipients, for 61 determinations at 48 hours was only $6.9 \mathrm{~mm}$. This low value appeared to be in part an attribute of the cells, since cells from the normal subject gave lesions that were somewhat more pronounced and averaged $8.3 \mathrm{~mm}$. The low average response was also greatly influenced by the complete nonreactivity of seven patients against one or more cells. On 11 occasions negative reactions were scored in this group of 73 determinations. In normal subjects only five negative reactions have been seen in several hundred readings. Arbitrarily we could divide the patients into three groups. Three patients were hyperreactive and had an average reaction against 12 foreign cell suspen- 


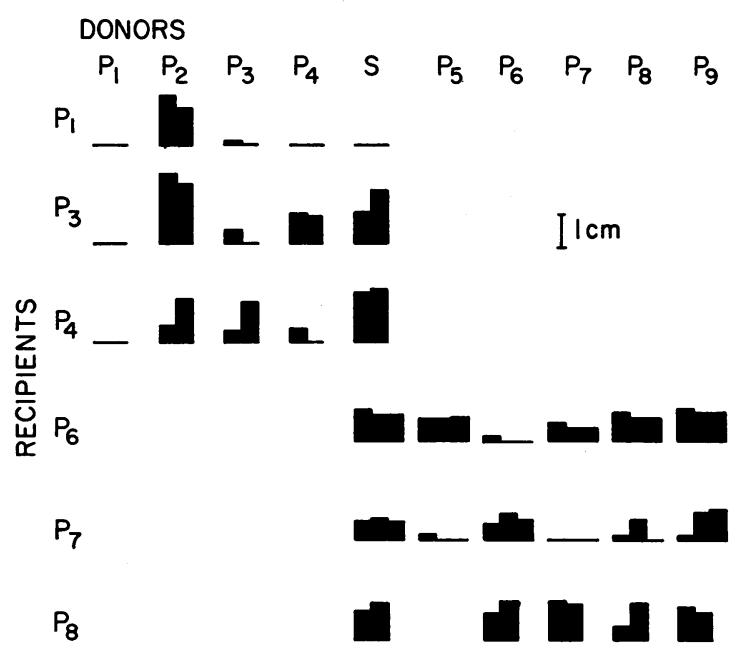

Fig. 5. A SELECTION OF TYPICAL RESUlTS OBTAINED IN PATIENTS WITH CELLS FROM A STUDENT (S) OR FROM PATIENTS WITH RESPIRATORY DISEASE. (Erythema measured at successive 24 hourly intervals.)

sions of $17.1 \mathrm{~mm}$ in diameter. Seven patients who failed to react against one or more cells had an inflammatory response of only $5.3 \mathrm{~mm}$ against the cells with which they did react; if this group is judged also by the negative reactions, the average falls to $3.1 \mathrm{~mm}$. The third group approximated more closely to normal subjects, but even in this group the average lesion was only $8.5 \mathrm{~mm}$ with cells from the patients and $8.7 \mathrm{~mm}$ with normal cells. The reaction appeared to be more dependent upon the state of the recipient than upon the cell itself, but in one instance one cell suspension failed to react in any of three recipients who were capable of reacting with cells from other donors.

In view of the uncertainty concerning the effect of immunity and especially of cellular immunity in malignant disease and because of the gross deviation of this group from the normal subjects in other tests, more extensive studies are planned. These will include attempts at correlation between reactivity in transfer tests and course of the disease.

\section{Discussion}

The immunological basis for the intradermal reactivity of transferred lymphoid cells has been established by a series of experiments by Brent, Brown, and Medawar in guinea pigs (20). Most of the experiments were carried out with lymph node cells. In these experiments it was shown that lymph node cells from normal donors did not react in normal recipients, that immunity could be demonstrated in circulating leukocytes within 3 days of the injection of antigen, and that the reaction had considerable specificity. Only two of ten non-inbred animals cross-reacted with cells specifically immunized against the inbred Heston strain. Reactions with lymph node cells from feebly immunized animals were negative or weakly reactive. Reactions with cells from strongly immunized animals were correspondingly strong, lesions up to $15 \mathrm{~mm}$ in diameter being produced with cells taken 10 days after immunization.

Although normal lymph node cells were nonreactive, transferred leukocytes from $2 \mathrm{ml}$ of peripheral blood from normal animals commonly induced very weak reactions. In four of 30 animals tested with normal blood leukocytes, stronger inflammation was observed (20). Differences between strong and weak reactions to cells from the same cell donor later formed the basis for the normal lymphocyte transfer test. By using a more highly purified lymphocyte suspension, Brent and

TABLE II

Reactions of sera from lymphocyte recipients against cells from lymphocyte donors*

\begin{tabular}{|c|c|c|c|c|c|c|c|c|c|c|c|c|}
\hline \multirow{3}{*}{$\begin{array}{c}\text { Recip- } \\
\text { ient's } \\
\text { sera }\end{array}$} & \multicolumn{12}{|c|}{ Donor cells tested } \\
\hline & \multicolumn{2}{|c|}{ A } & \multicolumn{2}{|r|}{ B } & \multicolumn{2}{|r|}{$\mathrm{C}$} & \multicolumn{2}{|c|}{$\mathbf{F}$} & \multicolumn{2}{|c|}{ G } & \multicolumn{2}{|c|}{$\mathbf{H}$} \\
\hline & Agg. & Cytotox. & Agg. & Cytotox. & Agg. & Cytotox. & Agg. & Cytotox. & Agg. & Cytotox. & Agg. & Cytotox. \\
\hline A & -- & -- & $+t$ & + & ++ & ++ & ++ & ++ & $+t$ & ++ & + & -- \\
\hline B & ++ & NT & -- & -- & + & ++ & +++ & -- & + & + & + & + \\
\hline C & ++ & ++ & + & ++ & -- & -- & ++ & + & ++ & -- & -- & -- \\
\hline $\mathbf{F}$ & $+t$ & NT & + & $++t$ & ++ & ++ & -- & -- & +++ & ++ & + & + \\
\hline G & + & -- & $+t$ & ++ & -- & +++ & + & ++ & -- & -- & -- & + \\
\hline $\mathrm{H}$ & ++ & ++ & ++ & NT & + & ++ & ++ & ++ & ++ & ++ & -- & -- \\
\hline
\end{tabular}

* Agg. and cytotox. $=$ leukoagglutination and cytotoxicity tests; -- , negative; + , weak positive; ++ , strong positive; +++ , complet 1 ; ; $1: 1$ atio $n$ or over $95 \%$ lysis; NT, not tested. 
Medawar could show that positive reactions were indeed quite frequent and could be correlated with the antigenic diversity among the animals (10). Finally they have established the genetic basis for the reaction in the guinea pig (11).

Collateral evidence for the extreme reactivity of peripheral lymphocytes comes from the experiments of Gowans (21) in which small lymphocytes from the thoracic duct converted to large pyroninophilic cells within 24 hours of intravenous injection, and from experiments in progress in our laboratory in which peripheral blood lymphocytes have converted to histiocytic cells within 18 hours of exposure to allogenic PMN in tissue culture.

Whereas peripheral lymphocytes from normal hosts appear to be highly reactive, cells from solid lymphoid organs appear to be less so. In the immune animal this distinction appears to disappear, and the reactions of immune cells described by Brent and his colleagues (20) appeared to be similar whether lymphocytes, peritoneal exudate cells, or lymph node cells were employed.

Many differences between man and guinea pig become apparent when results obtained from experiments in the two species are compared. Crossreactivity appears to be more widespread in man following the injection of normal cells, and the general level of reactivity is higher. Brent and Medawar have reported a number of $\mathrm{O}$ reactions and plus-minus (i.e., less than $2 \mathrm{~mm}$ ) reactions in the guinea pig (10). They specificially comment that a few of the reactions with normal cells were over $7 \mathrm{~mm}$ in diameter (10). In healthy human subjects negative reactions appear to be extremely rare; $5 \mathrm{~mm}$ is a common minimal reaction, lesions up to $32 \mathrm{~mm}$ have been seen, and the average reaction is over $10 \mathrm{~mm}$ in diameter. Host versus graft reactions do not appear to be bothersome in the guinea pig until after the third day, whereas in several of our experiments with PMN or platelets, host versus graft (h.v.g.), reactions were very common within 24 hours. Relatively few reactions appeared the second day, and, paradoxically, late reactions were more common in presensitized subjects.

Immunization of either the donor or the recipient greatly enhances the reaction in the guinea pig. Immunization does not greatly enhance the reaction in man, either in terms of the speed of the reaction, the minimal number of cells required to produce a lesion, or the extent of the lesion. There was also no evidence of increased reactivity when immune human cells were mixed with cells from an immunizing donor and injected into a neutral host. A similar test gave positive results in the guinea pig.

Many experiments can be carried out much more conclusively and simply in inbred strains of animals, especially since the results can be so readily checked on an identical animal, and genetic factors can be checked by the use of specific crosses. The differences between guinea pig and man cited above show that it is unfortunately not possible to extrapolate from the guinea pig to man.

The relatively poor reactivity of the immune recipient could be due to the rapid destruction of the transferred cells by the immunological reaction against them. The residual lesions in previously immunized subjects tended to fade completely within 7 days, whereas the injection site remained visible frequently for a month and occasionally for several months after primary injection. It is not so easy to explain the poor results obtained with cells from immunized subjects except perhaps by postulating allergic death of the injected cells. It is also difficult to explain how PMN can substitute for lymphocytes in some of the reactions. Yet this appears to be indicated in the experiments of Bridges and his colleagues (14). In some dosage experiments we have found a very close parallel between the reaction produced by the injection of a series of dilutions of lymphocyte suspensions of over $98 \%$ purity and a corresponding series of a crude PMN suspension in which only 10 to $15 \%$ of the cells were lymphocytes.

At present, extensive speculation upon the reaction in man is not justifiable, but it is possible to draw some conclusions that will form the basis for further studies.

1) Specific immunological reactions are involved. The reaction is directed against or mediated by the cells themselves. Autologous reactions to lymphocytes, PMN, or platelets generally are negative, and only three controls with autologous lymphocytes remained positive in healthy subjects at the end of 48 hours. Control tests with saline used to suspend the cells or with gelatin-contaminated plasma in which the 
cells were originally prepared were also negative.

2) Internal reproducibility is excellent if great care is taken with the intradermal injections. Subcutaneous inoculations or variations in the total volume destroy the reproducibility. Almost identical lesions are obtained with the same suspension in different sites of the forearm or immediately above the elbow.

3) Most of the subjects in the patient group reacted abnormally in two respects. Reactions to autologous cells were much more common in patients than in healthy subjects. The patients themselves had an impaired ability to react. Not only were the reactions to cells from other patients impaired, but the reactions to a test cell from a healthy donor were also moderately depressed. Some of the poor reactivity was also due to deficiencies of the cells. Complete failure to produce any inflammation was observed with cells from one subject, and isolated negative reactions were relatively common in these patients. Current experiments with Dr. B. Hattler have shown that the condition is not analogous to the situation in Hodgkin's disease, since the transferred cells can react to mumps and other commonly reactive antigens even in patients with advanced metastatic carcinoma. Lamb, Pilney, Kelly, and Good (22) have shown that nontoxic, noncachexic patients with carcinoma are not anergic to a variety of antigens. The depressed reactivity of the patients in our series to transferred lymphocytes and the contrasting higher reactivity of three of them warrant further investigation.

4) Host versus graft factors are prominent in the human. Reactions to PMN in allogenic hosts have been encountered when low numbers $\left(10^{8}\right)$ of PMN of $99 \%$ purity were injected and in the absence of nonspecific reaction in autologous hosts. The possibility of a pre-existent natural immunity in man must be considered although humoral antibodies have not been detected. Reactions to platelets and frozen and thawed lymphocytes were also occasionally positive in normal subjects. Sometimes the onset of reaction was delayed, suggesting a lag before the buildup of immunity, but more often the reaction was positive at 24 hours and might increase up to 48 hours just as the reaction with lymphocytes commonly built up to a maximum at 48 hours.
Experiments specifically designed to dissociate g.v.h. and h.v.g. responses by injecting immune cells into normal hosts or normal cells into immune hosts were not conclusive. The marked increase of reactivity observed in various animal species after immunization is much less marked in the human. That immunization had occurred was clearly shown in nine subjects who went on to produce circulating antibodies.

Graft versus host reactions cannot be clearly established from our experiments, since the immune cells appeared to show little of the aggressiveness characteristic of transfer experiments with immune cells in guinea pigs and other animals. In guinea pigs, peripheral blood cells from normal animals scored an average of a little over $2 \mathrm{~mm}$ in normal animals, compared to an average of 5 to $8 \mathrm{~mm}$ for immune cells in similar randomly assorted recipients. This is statistically highly significant. Over a large number of determinations there has been no statistical significance between the reactions of normal or immune cells in normal subjects.

5) PMN and platelets seem to carry fewer antigens than do lymphocytes. Since we cannot distinguish between h.v.g. and g.v.h. reactions when lymphocytes are injected, this difference cannot be put on a quantitative basis. The variability between experiments with frozen and thawed lymphocytes is disappointing in this respect. Nevertheless, negative reactions with lymphocytes are very rare; a number of negative reactions were observed with PMN, and many subjects were negative to platelets. It is also possible that the poor reactivity to certain lymphocyte suspensions in some patients is a reflection of impaired antigenicity in cells from cancer patients. Loss of antigenicity is known to occur in lymphomas but has not been documented in the leukocytes in carcinomas.

6) It is our belief that the test is greatly complicated by transitory fluctuations in the reactivity of subjects and by variations in reactivity between cell suspensions. These are common difficulties in biological testing but appear to be particularly dangerous in this test where comparisons between different subjects are being made. Subject $\mathrm{C}$ in experiment 3 appears to have been hyperreactive when the experiment was performed; this is reflected both in his re- 
actions to other cells and the reactions of his cells in other subjects. Similar and inconstant trends have been noted in other experiments. Variations may also be deduced from a careful consideration of the results of Brent and associates even when inbred strains were used (20). Brent and Medawar specifically caution against comparing the results obtained between tests (10).

The results presented by Gray and Russell show that the test can be useful in discriminating between potential skin donors $(12,13)$. It would be possible to obtain such a correlation irrespective of whether the reaction is g.v.h., h.v.g., or a compound of the two, since two subjects who are antigenically similar will tend to react feebly to each other. However, if the reaction is predominantly h.v.g., it may miss a number of potentially suitable donors and, more significantly, will recognize as suitable some who have antigens not present on the future recipient.

Before the test can be considered diagnostic of histoincompatibility in man, many more trials similar to those of Gray and Russell are unfortunately necessary, and these can only be conducted in man. The dangers of transmission of disease are known, but to these must be added the dangers of sensitizing a possible future recipient, and because of possible antileukocyte antibody formation or the transmission of transfer factor, the need to retire all cell recipients as future blood donors while circulating antibodies persist should be stressed. Because of inherent variability in the reactions of individual skin to injury, additional controls to give an indication of the basic reactivity of the various recipients are also necessary. The inclusion of a wide battery of noncellular and bacterial antigens would appear to be desirable. The true validity of the test can be established only through repeated trials and through the use of identical twins as cell recipients and later as skin graft donors.

\section{Summary}

Lymphocytes or purified suspensions of other cells from the blood of normal or immune subjects have been injected into human volunteers. The effects of variations in the immunological status of donor and recipient upon the lymphocyte transfer test for histocompatibility have been followed.
Immunization of the cell donor does not increase the reactivity of the injected cells, and immunization of the recipient tends to decrease the intensity and duration of the reaction.

Host factors are important in man. Normal recipients will react against polymorphonuclear neutrophils (PMN) or frozen and thawed lymphocytes. Reactions against these immunologically incompetent targets may be well developed within 24 hours of injection. Since cell free plasma and autologous cell controls were negative, reactions against $\mathrm{PMN}$ are considered to be an expression of a host versus graft response.

A depressed reactivity was observed in patients with carcinoma of the lung. PMN and platelets from normal subjects and some lymphocyte suspensions from patients have a more restricted range of reactivity than normal lymphocytes. This suggests antigenic deficiencies in these cells.

The lymphocyte transfer test, while apparently valid as a test for histocompatibility in the guinea pig, is complicated in man by poor reproducibility, by host reactions against the injected cells, and possibly by a state of natural immunity against some leukocyte antigens.

\section{References}

1. Dausset, J. Leuco-agglutinins IV. Leuco-agglutinins and blood transfusion. Vox Sang. (Basel) 1954, 4, 190.

2. Van Rood, J. J., and A. van Leeuwen. Defined leukocyte antigenic groups in man in Histocompatibility Testing. Washington, National Academy of Sciences-National Research Council, publication 1229,1965 , in press.

3. Payne, Rose, M. Tripp, J. Weigle, W. Bodmer, and J. Bodmer. A new leukocyte iso-antigenic system in man. Cold Spr. Harb. Symp. quant. Biol. 1964, 29, in press.

4. Terasaki, P. I., T. L. Maichiori, and T. E. Starzl. Sero-typing of human lymphocyte antigens: preliminary trials on long-term kidney homograft survivors in Histocompatibility Testing. Washington, National Academy of Sciences-National Research Council, publication 1229, 1965, in press.

5. Friedman, E. A., J. W. Retan, D. C. Marshall, L. Henry, and J. P. Merrill. Accelerated skin graft rejection in humans preimmunized with homologous peripheral leukocytes. J. clin. Invest. 1961, 40, 2162.

6. Rapaport, F. T., L. Thomas, H. S. Lawrence, J. M. Converse, W. S. Tillett, and J. H. Mulholland. Skin homograft sensitivity cross reactions in man. Ann. N. Y. Acad. Sci. 1962, 99, 564. 
7. Metzgar, R. S., and J. F. Flanagan. Mixed agglutination technique for the detection of isoantigens on human kidney cells in Histocompatibility Testing. Washington, National Academy of SciencesNational Research Council, publication 1229, 1965, in press.

8. Bain, B., M. Vas, and L. Lowenstein. The development of large immature mononuclear cells in mixed leukocyte cultures. Blood 1964, 23, 108.

9. Bach, F., and K. Hirschhorn. Lymphocyte interaction: a potential histocompatibility test in vitro. Science 1964, 143, 813.

10. Brent, L., and P. B. Medawar. Tissue transplantation: a new approach to the "typing" problem. Brit. med. J. 1963, 2, 269.

11. Brent, L. Some remarks on the present state of the problem of tissue typing in Histocompatibility Testing. Washington, National Academy of Sciences-National Research Council, publication 1229, 1965 , in press.

12. Gray, J. G., and P. S. Russell. Donor selection in human organ transplantation. A possible screening test. Lancet 1963, 2, 863.

13. Gray, J. G., and P. S. Russell. The lymphocyte transfer test in man in Histocompatibility Testing. Washington, National Academy of Sciences-National Research Council, publication 1229, 1965, in press.

14. Bridges, J. M., S. D. Nelson, and M. G. McGeown. Evaluation of lymphocyte transfer test in normal and uræmic subjects. Lancet 1964, 1, 581.
15. Payne, R., and M. Rolfs. Fetomaternal leukocyte incompatibility. J. clin. Invest. 1958, 37, 1756.

16. Payne, R. Leukocyte agglutinins in human sera. Correlation between blood transfusions and their development. Arch. intern. Med. 1957, 99, 587.

17. Greenwalt, T. J., M. Gajewski, and J. L. McKenna. A new method for preparing buffy coat-poor blood. Transfusion (Philad.) 1962, 2, 221.

18. Amos, D. B., and N. Peacocke. Leucoagglutination. A modified technique and preliminary results of absorption with tissues. Proc. IX Cong. Europ. Soc. Haematology. Lisbon, Basel, New York, Karger, 1963, p. 1132.

19. Walford, R. L., R. Gallagher, and J. R. Sjaarda. Serologic typing of human lymphocytes with immune serum obtained after homografting. Science 1964, 144, 868.

20. Brent, L., J. B. Brown, and P. B. Medawar. Quantitative studies on tissue transplantation immunity. VI. Hypersensitivity reactions associated with the rejection of homografts. Proc. roy. Soc. B 1962, $156,187$.

21. Gowans, J. L. The fate of parental strain small lymphocytes in $F_{1}$ hybrid rats. Ann. N. Y. Acad. Sci. 1962, 99, 432.

22. Lamb, D., F. Pilney, W. D. Kelly, and R. A. Good. A comparative study of the incidence of anergy in patients with carcinoma, leukemia, Hodgkin's disease and other lymphomas. J. Immunol. 1962, 89, 555 . 